\title{
Services Systems to Leverage Innovators' Knowledge: The Telecoms Industry Case
}

\author{
Florie Bugeaud $^{1,2}$ and Eddie Soulier ${ }^{1}$ \\ ${ }^{1}$ University of Technology of Troyes - ICD/Tech-CICO FRE CNRS 2848, \\ 12 rue Marie Curie - BP2060, 10010 Troyes Cedex, France \\ firstname. namedutt. fr \\ ${ }^{2}$ Orange Labs, 38-40 rue du Général Leclerc, 92794 Issy-les-Moulineaux \\ florie. bugeaudeorange-ftgroup.com
}

\begin{abstract}
Today, telecoms operators have to prove their innovation capacity. They address corporate customers which are involved in collaborative value networks. They implement a process of new services research in order to create adapted solutions. This process is linked to a collaborative and complex practice between diverse innovators. However there is no structured method to leverage this community's knowledge. Based on the $\operatorname{SSME}^{1}$ discussions, we suggest enriching the telecoms innovation approaches by the representation and the simulation of "services systems". This paper also proposes the development of a collaborative tool to support this suggestion and the innovators' practices. Our approach is currently tested on a specific telecom service in the e-health domain which presents an interesting business ecosystem.
\end{abstract}

Keywords: SSME, Service System, Innovation, Knowledge.

\section{Introduction}

The telecoms industry is a major actor in the innovation of services. It addresses corporate customers which are more and more involved in value networks. This engagement with business partners stems from the transformation from an organizational view (integrated model) to a market view (specialized and distributed model). It corresponds to the outsourcing logic and brings flexibility and agility. Moreover, this opening creates a broader range of market opportunities [1]. Telecoms operators have to take into account these complete value networks in order to propose them adapted and innovative services. Albeit the literature is comprehensive about the products innovation, there is not a lot of works on the design of innovative services. The lack of a structured method and the dispersal of the actors limit the innovators' reasoning of design. This reasoning is linked to a collaborative and complex practice underlying the process of innovative services research. According to Precup and al. [2] "the cross fertilisation of thoughts and ideas and knowledge generation is without doubt one of the key success factors to promote a culture of innovation". Indeed, the knowledge sharing and co-creation during the service design is an essential factor to improve the

\footnotetext{
1 "Services Science Management and Engineering": initiated by IBM and some universities.
} 
creativity. It is thus necessary to bring a structured framework and a shared representation in order to support the innovators' work. The SSME discipline proposes an interdisciplinary approach gathering all the synergies around the notion of "service". This paper pursues the ongoing discussions of SSME [3]. It suggests conceiving the service as a "Service System" and it studies the knowledge models allowing its emergence. One of the difficulties is linked to the service modeling because it does not have a specific formalization. The design reasoning of innovators is based on two spaces: the concepts and the knowledge (C-K theory [4]). Our works represent the distributed character of the telecoms innovators thanks to a social network [5]. They use the usual mechanisms of social networks to spread the design reasoning of innovators through their own social network. Our mechanism is based on the diffusion of forms and the use of tagged knowledge in order to co-create our models. Finally, our approach is currently tested on a specific telecom service in the e-health domain (the remote monitoring of diabetic patients) whose business ecosystem is complex and demanding. This application of our hypotheses and models will be the object of more specific publications.

This paper is organized as follow. The section 2 presents the context of the services innovation in telecoms operators. The section 3 introduces the identification of services and the modeling of services systems. The section 4 describes the main functionalities of the proposed tool (co-creation of models through the diffusion of forms, enrichment of a Services Systems repository, simulation/animation of the Service System, connection between the tags of the existing telecoms offer and the tags of the Service System). The section 5 concludes this paper.

\section{Services Innovation in the Telecoms Industry}

\subsection{The Value Network of the Corporate Customers}

In today's challenging global market, telecoms operators need to innovate in order to support the value creation of their corporate customer. The evolution of Information and Communication Technologies (TIC) has brought new ways to design and to deliver services. Moreover a lot of economic, organizational and sociologic evolutions have brought new issues. Telecoms operators try to remain competitive and to answer the evolution of their customers' requirements and organization. Their corporate customers are more and more involved in value networks. Indeed, we are currently living a transformation from an organizational view to a market view. This hypothesis criticizes the integrated model in favor of a specialized and distributed model. It considers companies as sets of business components involved in a value network. These components are "strategic areas" stemming from the junction of the value chain and the strategic segments (classical approach) or "business components" which are autonomous and logical groupings of people, technologies and resources whose objective is to deliver value (cf. Component Business Modeling methodology from IBM). Each company is specialized on a specific business domain and uses its partners' services when it is necessary. It corresponds to the outsourcing logic and it brings flexibility and agility. 
For example, telecoms operators are more and more interested in services sectors such as the healthcare sector. They address the whole business ecosystem of the ehealth field (Fig. 1) and propose new offers including telecoms products (telephony, networks), solutions (e.g. collaborative work, mobility) and pure services (e.g. project management, consulting). This requires having a complete view of the value network in which these actors are business partners.

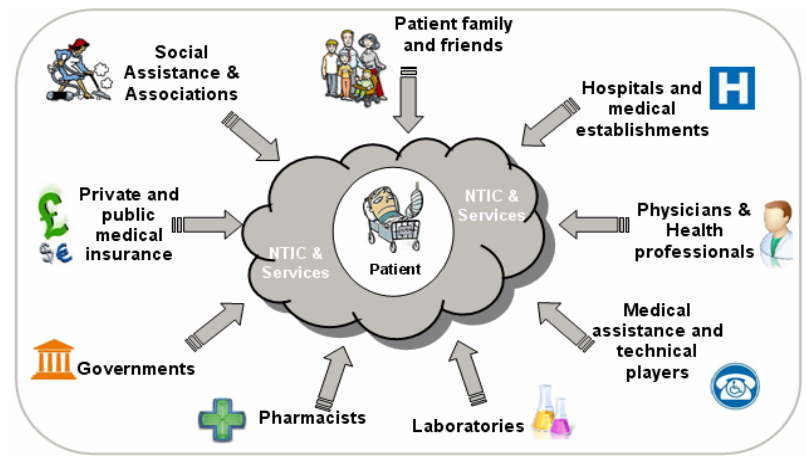

Fig. 1. The e-health business ecosystem: example of a complex and demanding business ecosystem which is addressed as a whole by the telecoms operators

\subsection{The Design Process and Design Reasoning in Telecoms}

In the telecoms industry, the design process is generally shared between four main departments (marketing, research and development, exploration centre, technologic centre) and three key moments (research, development, market entry) (Fig. 2). Their innovators come from several disciplines (marketing, usages experts, ergonomics, engineers, etc.). They initiate a sub-process upstream of the design process (at $\mathrm{T}-1$ in Fig. 2) in order to research ideas of innovative telecoms services. The ideas or concepts go through three phases: evaluation, maturation and transfer (Fig. 2). Each phase is overseen by a decision committee. A reading committee makes a first selection of concepts and determines the actions plan. An anticipation committee selects the major enriched concepts and validates their transfer towards the design process at T0. This process usually includes the analysis of the sector, practices and business processes of the targeted corporate customer, and the detection of opportunities. Nevertheless, the global "service orientation" (growth of the tertiary sector and evolution of companies) has brought new issues. It is necessary to adapt the methods of telecoms operators to take into account the services specificities.

In addition, the success of this new services research process is based on the design reasoning and the interactions between the telecoms innovators. This reasoning is an analytic and cognitive process. The shared information and arguments give rise to a collaborative and complex practice in a specific community. These innovators work as a virtual team in a network environment such as the designers involved in a collaborative creativity of products concepts [6]. The emergence of a new concept or idea of service starts the design process. It needs and develops their individual and collective knowledge. Nevertheless, their actual collaboration is insufficient to reach 
the necessary sharing and co-creation of knowledge. There are two reasons. The former is that these innovators often prefer to share information into their personal network. The latter is that there is no structured method and that the existing modeling environments are not adapted. It is thus important to bring them a method and an associated tool to help them to collaborate and to share their knowledge.

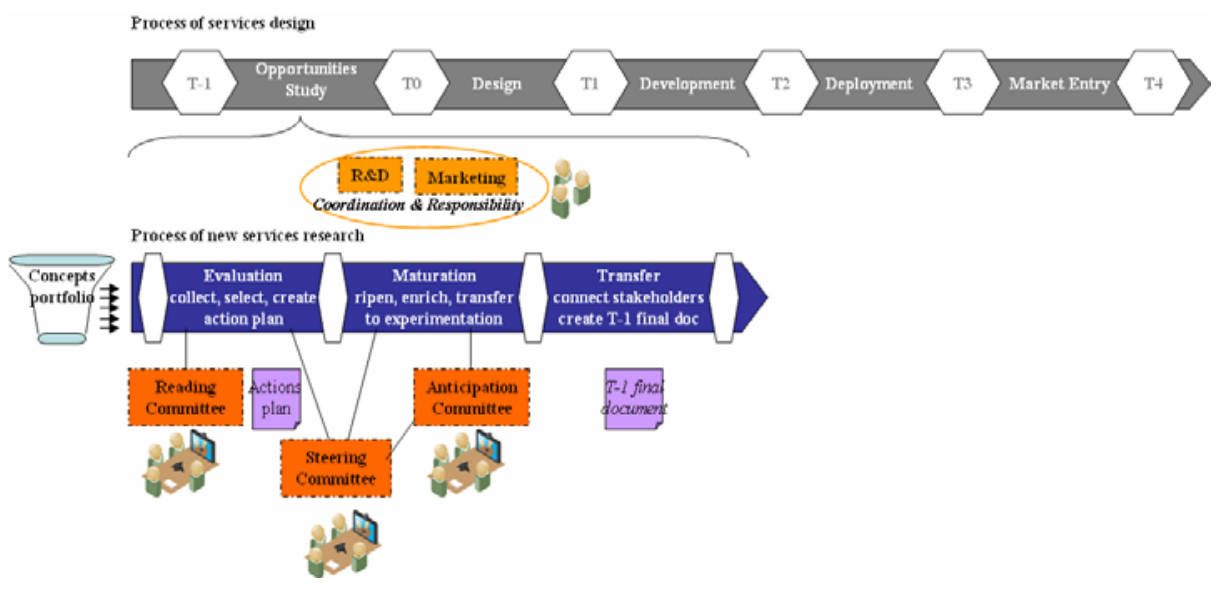

Fig. 2. The innovation processes in the telecoms industry: main milestones, stages, actors and deliverables

\section{Service as a Service System}

\subsection{Identification of Services}

The notion of "service" [7] remains hazy because of its several dimensions and characteristics such as its intangibility, its heterogeneity, the interactions between customers and providers, the coproduction by all the stakeholders, etc. The SSME field has proposed a notion of service which is more abstract than the one usually find in the literature. Indeed, the implementation dimension is predominant. It defines the service as a reusable technical functionality. Our works pursue the ongoing discussions of SSME. We distinguish three approaches to identify these services:

- a top-down approach based on business components or strategic domains,

- $\quad$ an intermediary approach based on the requirements and business goals,

- $\quad$ a bottom-up approach based on existing tools, applications, technologies...

The notion of "service" regroups static and dynamic aspects. In order to express this complexity, some researchers of the SSME discipline propose the term "Service System" [8]. They define it as "a value-coproduction configuration of people, technology, other internal and external service systems, and shared information". We conceive the "Service System" through the "Service Concept" and the "Service Delivery System" (Fig. 3). Indeed in the field of innovation, it is necessary to conceive at the same time the concept of service, the targeted customers' segment and the system for its functioning [9]. 


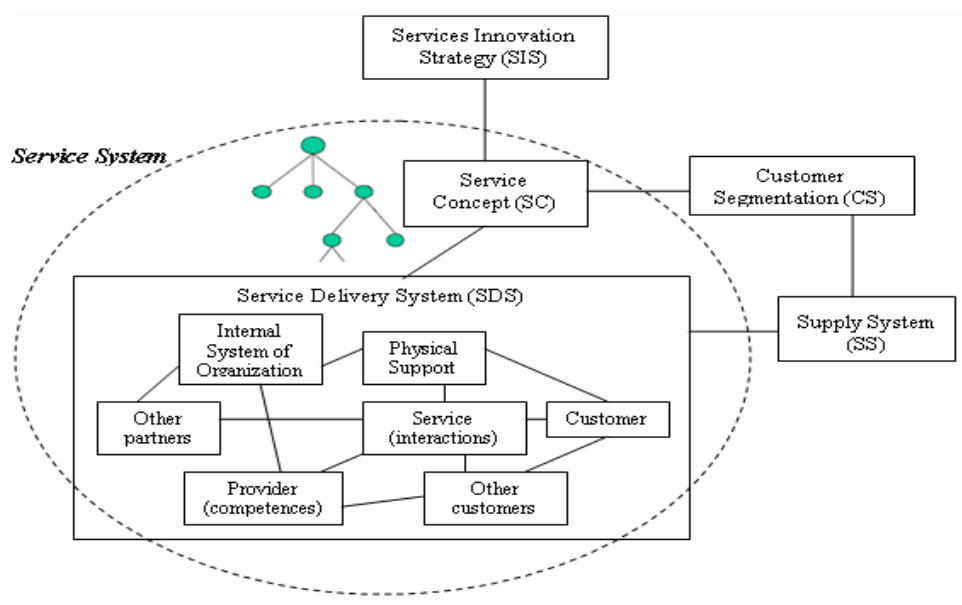

Fig. 3. The Service System: main elements

\subsection{Service System: The Service Concept (SC)}

Even if they focus on "products concepts", Volpentesta and al. [6] suggest that:

- the "concept development" is the first phase of the product development process,

- the "concept design" is relative to the work done by designers (task clarification, hypothesis formulation, solution searching) in order to determine an architecture,

- the design participants come from different disciplines and generate the "seeds of innovation" (i.e. the ideas for a new product concept) in a collaborative way.

In the same spirit, but within the context of services innovation, the "Service Concept" (SC) corresponds to the idea or object of the innovation for a targeted customer or activity sector. In 1989, Scheuing and Johnson defined a "concept" as "a description of a potential new service" [9]. For example, in the telecom industry there are the services of mobility, connectivity, security, cooperation or geolocalisation. We can also note some examples of a "Customers Segmentation": SMEs in the sustainable development, banks, insurance companies or hospitals. The initial SC can be broken down into sub-concepts which can be themselves broken down in an iterative way. This can be called a functional breakdown [10] with basic services and peripheral services. The SC presents a tree based structure [4] [9]. This design tree needs and develops the innovators' knowledge. It helps them to progress in the exploration of relevant concepts that may become designed and sold objects.

\subsection{Service System: The Service Delivery System (SDS)}

The "Service Delivery System" (SDS) is the hypothetic functioning of the "Service Concept" (SC). The SDS is linked to the notion of "servuction" which has been proposed by Eiglier and Langeard in 1987. It includes the customer, the physical support, the providers' employees (which are in front of the customer), its internal system of organization and the service as the result of interactions. Our works add to these ele- 
ments the nature of the service target or medium (material, knowledge, information, relation) [10], the other customers and partners of the services provider. A SDS is thus composed of several facets which depend on six mains views: strategy, provider, customer, services interactions, information systems and technologies. The initial servuction model considers the back-office of the services providers as a black box. Nevertheless, this back-office comes from their internal system of organization and it is a key element for the service furniture and support. The usual distinction between back-office and front-office is insufficient in the case of services. We can distinguish two other spaces: the back-stage and the on-stage. The line between them depends on the visibility and the implication of the customer who access a part of the provider's front-office. Another distinction is linked to the results of the Service System: the output and the outcome. The former is a short-term result or immediate effect. The latter is a more long-term result or useful effect.

\section{Supporting Tool for the Community of Innovators}

\subsection{Diffusion of Forms in a Social Network}

The process of new services research needs the sharing of more or less tacit and individual knowledge between innovators. It also needs a shared representation of the Service System which has to be imagined. We have decided to represent the distributed telecoms innovators thanks to a social network [5]. The proposed web-based tool uses a method (Fig. 4) inspired from the usual mechanisms of social networks. It aims at facilitating the exchanges between innovators and stimulating their work. In an asynchronous and distributed way, the steps are:

- breakdown of the Service System models into several forms (always available),

- proposition of a research theme by an innovator or a group of innovators,

- diffusion of the forms in the social network according to the profiles,

- enrichment and registration of these forms by the targeted innovators who accept to participate to the Service System description,

- enrichment of the Services Systems repository based on the registered forms,

- generation of the Service System models and consolidation of the repository.

It is also possible to make some request in the Services Systems repository. Finally, this tool can also be used in a direct access by an innovator or a working group (e.g. during a brainstorming) to model the Service System. This working environment is based on a wiki in order to ease innovators' interactions (see the ANR ISICIL ${ }^{2}$ and the SweetWiki in which the use of semantic web technologies is investigated to support and ease the lifecycle of the wiki [11]).

\subsection{Connection with the Existing Services and Knowledge through Tags}

Tags are keywords or descriptive terms. The process of tagging is a powerful tool to organize objects for the purposes of recovery, sharing and discovery them, when

\footnotetext{
${ }^{2}$ Information Semantic Integration through Communities of Intelligence online (http://isicil.inria.fr/)
} 
combined with search technology [12]. The existing expertise and knowledge (K) and the existing telecoms services are already tagged. The addition of tags on the designed new Service System during its description brings an interesting help. Indeed, these tags are key elements for the connection between the existing telecoms supply system, services and know-how, and the current concept (C) (C-K theory [4]) of Service System. The proposed tool allows this automatic connection. Indeed it supports the emergence of ideas by the detection of possible adaptations of existing services to a new requirement. It proposes this kind of suggestions to the innovators which can decide if such adaptations are pertinent.

\subsection{Animation, Annotation and Validation of the Service System}

Some existing solutions allow the generation of an ergonomic expression of processes. They model and simulate these processes and their associated micro-world. This kind of tool is useful for the communication, the usages illustration and the validation of a hypothetic functioning. That is why it seems interesting to propose the generation of an animation of the Service System after the consolidation of the repository (Fig. 4). The result is a pretty realistic animated scene. This virtualized Service System (and its context) can help innovators to have a common representation stemming from their individual and collective contributions. They can discuss and exchange some commentaries and annotations based on this animation. After some hypothetic modifications of the models or forms (to obtain a more pertinent simulation/animation), they validate the Service System and transfer it to the design team (towards $\mathrm{T} 0$ as it has been described in the section 2.2).

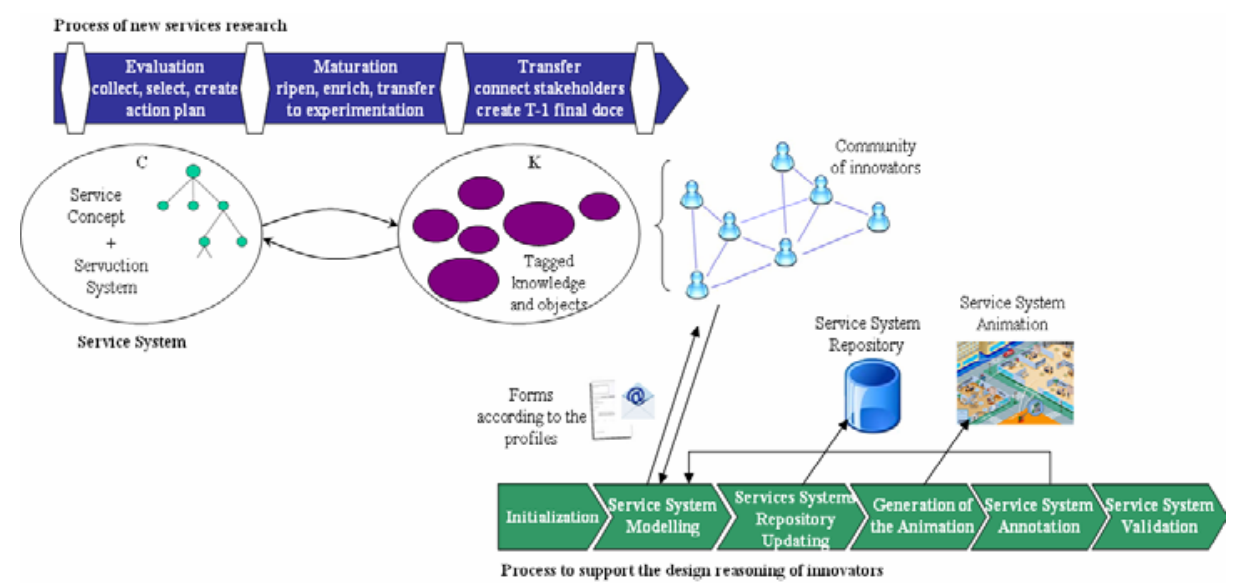

Fig. 4. A collaborative method and tool to support the innovators reasoning

\section{Conclusion}

The current tools and approaches to generate ideas for innovation are mainly based on the process modeling. Moreover they are focused on integrated companies and do not really take into account the entire business ecosystem involved. Our works propose to 
take into account the Service System as a whole in order to improve these tools and approaches. The proposed methodology aims at the identification and characterization of the "Service Concept" and the "Service Delivery System". It allows the leveraging and sharing of innovators' knowledge in order to obtain a shared representation. Innovators expand their knowledge, annotate and validate a new idea of Service System. Its animation helps them to visualize its hypothetic functioning. Finally the enriched repository brings available information for further services.

The next stages of our works concern the improvement of the Service System formalisms in order to take into account the collaboration, information and interaction issues. Moreover, because the e-health is a priority sector for telecommunications operators and an interesting field to test our hypotheses and models, we apply our approach to the remote monitoring of diabetic patients.

\section{References}

1. Rajsiri, V., Lorré, J.-P., Bénaben, F., Pingaud, H.: Collaborative process definition using an ontology-based approach. In: Camarinha-Matos, L., Picard, W. (eds.) Pervasive Collaborative Networks. IFIP, vol. 283, pp. 205-212. Springer, Boston (2008)

2. Precup, L., Mulligan, D., O’Sullivan, D.: Collaborative tool to support knowledge sharing and innovation in an R\&D Project. In: International Conference of Concurrent Engineering, Espoo, Finland (2003)

3. Glushko, R.J.: Designing a service science discipline with discipline. IBM Systems Journal (2008)

4. Hatchuel, A., Weil, B.: A new approach of innovative design: an introduction to C-K theory. In: ICED, Stockholm (2003)

5. Newman, M.: The Structure and Function of Complex Networks. SIAM Review 45, 167 (2003)

6. Volpentesta, A.P., Muzzupappa, M., Ammirato, S.: Critical thinking and concept design generation in a collaborative network. In: Camarinha-Matos, L., Picard, W. (eds.) Pervasive Collaborative Networks. IFIP, vol. 283, pp. 157-164. Springer, Boston (2008)

7. Gadrey, J.: The characterization of goods and services: an alternative approach. Review of Income and Wealth 43(3) (2000)

8. Spohrer, J., Maglio, P., Bailey, J., Gruhl, D.: Steps Towards a Science of Service Systems. IEEE Computer 40, 71-77 (2007)

9. Lenfle, S.: Innovation in services: the contributions of design theory. In: 11th IPDMC Conference Trinity College. Dublin (2004)

10. Gallouj, F., Weinstein, O.: Innovation in services. Research Policy 26, 537-556 (1997)

11. Buffa, M., Crova, G., Gandon, F., Lecompte, C., Passeron, J.: SweetWiki: Semantic WEb Enabled Technologies in Wiki. In: 1st Workshop on Semantic Wikis, 3rd ESWC, Montenegro (2006)

12. Xu, Z., Fu, Y., Mao, J., Su, D.: Towards the Semantic Web: Collaborative Tag Suggestions. In: Proceedings of the Collaborative Web Tagging Workshop, WWW 2006, Edinburgh (2006) 